\title{
Cancer therapeutics and research: novel developments
}

\author{
GJ Peters \\ Correspondence: gj.peters@vumc.nl \\ Department of Medical Oncology, VU University Medical Center, Amsterdam, Netherlands.
}

\section{Editorial}

Current cancer treatment still faces many challenges, while drug development and consequently novel treatments lag behind. Treatment of cancer has made tremendous progress in the last few decades. For example, childhood cancer in the developed countries can be cured for the majority of patients, but as demonstrated in a paper in the first volume [1], lags behind in developing countries. Unfortunately, this is often caused by lack of resources, but also by ignorance of the health authorities and of cancer patients. However, education of both the physician and the patient will increase admittance to specialized hospitals and improve treatment outcome. This also will help to characterize differences in genetic properties, which are often found between these ethnic populations. This will help to personalize treatment, first for the ethnic group, but with the ultimate aim for the individual patient.

Progress in cancer treatment can be achieved by novel approaches and developing intelligent combinations of DNA- and novel protein kinase (both tyrosine and serinethreonine) targeted drugs. DNA-targeted drugs often trigger survival pathways which can subsequently be inhibited by a tyrosine kinase inhibitor. Progress also can be achieved by improval of currently available technologies, such as surgery and radiotherapy. When state-of-the-art technology common in developed countries is not available, improvement has to be achieved by clever use of existing technologies. Other ways to improve cancer treatment is the application of existing therapeutic modalities from non-cancer diseases to cancer.

In the first volume of Journal Cancer Therapeutics and Research (JCTR) papers describing the above-mentioned approaches have been published. The challenge of a new journal is to find either a niche or a wider scope which is attractive for either a limited group of scientists or for scientists with a broad interest, respectively. The journal has chosen the latter encompassing molecular pathobiology, cellular pathobiology, tumor and stem cell biology, metastasis, tumor suppressor, microenvironment and immunology, prevention and epidemiology, integrated systems and technology, and therapeutics and targets. Using this approach we have been able to publish papers on Epidemiology, Genetics and Genomics, Molecular Diagnostics, Translational Therapeutics and Clinical Studies of Cancer Research. However, not each category is equally distributed, and we aim to attract more papers in the field of genetics and genomics, knowledge which can be applied to personalize treatment with either DNA targeted drugs, protein kinase targeted drugs, combinations or a combination with modern radiotherapeutic approaches such as 3-and 4-dimensional radiation. Selection of patients is the future, such as being investigated in several large prospective studies which perform either whole genome sequencing or limited screening for a few genes. In general, sequencing of the whole genome in large groups will help to identify potential druggable targets, while screening for a few selected genes will be more useful to identify patients most likely to respond to a certain treatment.

With the dedicated help of the senior editors Piero Picci, Hallgeir Rui, Paolo Fortina, Jacques E. Nor and Jiaoti Huang we have been able to warrant a high quality in different fields. They have a large experience covering many fields of cancer research, and have been supported by critical reviewers who reviewed rigorously the submitted papers. Of these submissions $55 \%$ has been rejected after initial review and evaluation, by either the senior editor or by the Editor-In-Chief. Hence, quality was assured in this process. Accepted manuscripts cover several areas such as research on a large variety of topics (apoptosis, cell cycle modulation, surgery, radiation, cachexia, tyrosine kinases, prevention, biomarkers) [2,3,4], clinical studies (covering many cancers, mostly focusing on single-institutional studies, although large databases also were used) [5], novel methodologies (metronomic therapy, but also radiation and surgical approaches) $[5,6,7,8,9]$, and case reports (Figure 1). The latter was somewhat surprising and had special attention of the editors, since a case report should really describe novel aspects of a certain disease. A good case report will focus on unexpected findings in certain patients or patients group, and therefore needs to be very focused not only on findings in such patients but also be able to put these data in a wider perspective. Additionally, several reviews $[8,10]$ and hypothesis generating papers [11] were published.

Where are we heading? The Journal has made an excellent start, since it is not easy to attract high quality papers. However, to become visible, to be covered by indexing sources such as PubMed, and to attract more

(c) 2013 GJ Peters licensee Herbert Publications Ltd. This is an Open Access article distributed under the terms of Creative Commons Attribution License (http://creativecommons.org/licenses/by/3.0). This permits unrestricted use, distribution, and reproduction in any medium, provided the original work is properly cited. 


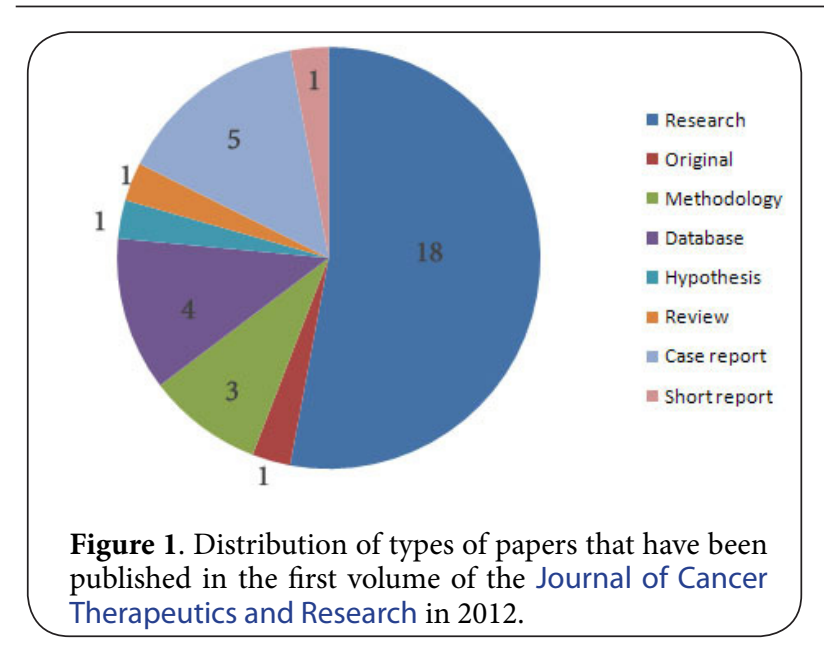

outstanding manuscripts, the current strict editorial policy has to be maintained and even strengthened more. The Journal is on the right track, although there is much competition in this field, but the publisher is dedicated to provide the resources to maintain the current quality of the papers and the rapid review process. We continue to attract exciting papers on various topics. Because of the rapid processing (time between submission and final acceptance 45 days), publication (within 7 days after acceptance) will be timeless. We solicit, among various items, high quality research papers, reviews on contempary topics and reports on clinical studies.

\section{Competing interests}

The author declare that they have no competing interests.

\section{Acknowledgement}

I thank the senior editors, the editorial board members and the reviewers for their continuing efforts in reviewing papers and the senior editors for their comments to this editorial. I also want to thank the excellent support from the editorial office members during the first year and for providing me with the information to write this editorial.

\section{Publication history}

Received: 22-Feb-2013 Revised: 04-Mar-2013

Accepted: 04-Mar-2013 Published: 07-Mar-2013

\section{References}

1. Supriyadi E, Veerman AJ, Sutaryo S, Purwanto I, vdVen PM and Cloos J: Detection of CD10, CD34 and their combined expression on Childhood Acute Lymphoblastic Leukemia and the association with clinical outcome in Indonesia. Journal of Cancer Therapeutics and Research 2012, 1:20. | Article

2. Åhlén J, Westerdahl J, Zedenius J, Bränström R, Larsson C and Nilsson I L: Side-effects from imatinib treatment of advanced GISTassociated with a better outcome. Journal of Cancer Therapeutics and Research 2012, 1:11. | Article

3. Gagliardi $G$ and Bellows CF: DCLK1 expression in gastrointestinal stem cells and neoplasia. Journal of Cancer Therapeutics and Research 2012, 1:12. | Article

4. Vetvicka V: Procathepsin D in cancer development. Journal of Cancer Therapeutics and Research 2012, 1:22. I Article

5. Hirshoren N, Cohen J, Neuman T, Weinberger JM and Eliashar R: Is Surgery for an FNA proven Warthin's Tumor Passé? Journal of Cancer
Therapeutics and Research 2012, 1:9. | Article

6. Kumar Pant N, Singh A and Kumar D: Multiple brain metastases from primary gall bladder carcinoma treated by sequential surgery, radiotherapy and chemotherapy. Journal of Cancer Therapeutics and Research 2012, 1: 8. | Article

7. Carrafiello G, Cardim LN, Floridi C, Piacentino F, Massa AD, lerardi AM and Fugazzola C: Patient selection - clinical and imaging criteria - for percutaneous lung malignancies ablation: a single centre experience and a literature review. Journal of Cancer Therapeutics and Research 2012, 1:23. | Article

8. Mross K and Steinbild S: Metronomic anti-cancer therapy - an ongoing treatment option for advanced cancer patients. Journal of Cancer Therapeutics and Research 2012, 1: 32. | Article

9. Lobbes M, Prevos R and Smidt M: Response monitoring of breast cancer patientsreceiving neoadjuvant chemotherapy using breast MRI - a review of current knowledge. Journal of Cancer Therapeutics and Research 2012, 1: 34. | Article

10. Singh $P$ and Singh A: Ocular adverse effects of Anti-cancer Chemotherapy. Journal of Cancer Therapeutics and Research 2012, 1:5. | Article

11. Kast RE: Epithelial ovarian cancer: A feasible plan for adjunctive treatment using simultaneous acyclovir, ambrisentan, captopril, disulfiram, fluvoxamine-augmented ramelteon, icatibant, imiquimod peritoneal lavage, and plerixafor. Journal of Cancer Therapeutics and Research 2012, 1:2. | Article

\section{Citation:}

Peters G: Cancer therapeutics and research: novel developments. journal of Cancer Therapeutics and Research 2013, 2:12.

http://dx.doi.org/10.7243/2049-7962-2-12 